\title{
A sociedade de austeridade: Poder, medo e direito do trabalho de exceção
}

The Austerity Society: Power, Fear and the Right to Work in a "State of

Exception"

La société d'austérité : pouvoir, peur et droit du travail d'exception

\section{António Casimiro Ferreira}

\section{OpenEdition}

\section{Journals}

\section{Edição electrónica}

URL: http://journals.openedition.org/rccs/4417

DOI: $10.4000 /$ rccs. 4417

ISSN: $2182-7435$

\section{Editora}

Centro de Estudos Sociais da Universidade de Coimbra

Edição impressa

Data de publição: 1 Dezembro 2011

Paginação: 119-136

ISSN: 0254-1106

\section{Refêrencia eletrónica}

António Casimiro Ferreira, « A sociedade de austeridade: Poder, medo e direito do trabalho de exceção », Revista Crítica de Ciências Sociais [Online], 95 | 2011, colocado online no dia 01 dezembro 2012 criado a 19 abril 2019. URL : http://journals.openedition.org/rccs/4417 ; DOI : 10.4000/rccs.4417 


\title{
ANTÓNIO CASIMIRO FERREIRA
}

\section{A sociedade de austeridade: Poder, medo e direito do trabalho de exceção}

\begin{abstract}
Neste artigo identificam-se algumas das consequências sociojurídicas da implementação das medidas de austeridade, prestando-se especial atenção às alterações introduzidas na esfera laboral. Partindo de uma discussão geral em torno da noção de sociedade da austeridade, o autor desenvolve uma análise crítica centrada nas questões do medo social e do poder. No quadro da sua perspetiva de análise sugere que o conceito de direito do trabalho de exceção ilustra os resultados não democráticos da aplicação das medidas de austeridade.
\end{abstract}

Palavras-chave: medidas de austeridade; sociedade da austeridade; sociologia do direito do trabalho; relações laborais.

\section{Introdução}

"Matar o doente pela cura" e "eu é que estou a pagar o que outros fizeram" são duas expressões escutadas com frequência e aceites com maior ou menor resignação. Elas consubstanciam perplexidades suscitadas por essa palavra mágica dos dias de hoje: austeridade. É uma palavra-ação por estar ligada ao ato de austerizar ou de tornar austero, significando, neste artigo, o processo de implementação de políticas e de medidas económicas que conduzem à disciplina, ao rigor e à contenção económica, social e cultural.

$\mathrm{Na}$ atualidade, o que confere especificidade sociológica ao conceito é o reconhecimento de que é através dos indivíduos e das suas privações subjetivas e objetivas que se encontram as soluções para a crise composta pela nebulosa dos mercados financeiros, do défice público do Estado e dos modelos económicos e sociais seguidos nos últimos anos.

Orientado por esta linha de argumentação, sustento que a noção de austeridade se configura como o "padrão que liga" (Bateson, 1987: 17) os problemas sistémicos, predominantemente financeiros, às interpelações aos indivíduos, às famílias e às organizações colocadas perante uma política de "requisição civil". Esta assenta numa ética cínica que confere um 
caráter excecional à utilidade do social enquanto fonte de resposta à crise, manifestando todavia indiferença quanto aos danos resultantes do aumento das desigualdades, do empobrecimento e do mal-estar social. A espiral da austeridade constitui um teste de resultados cada vez mais imprevisíveis aos limites da vida democrática e da coesão social.

A reflexão aqui desenvolvida procura contribuir para uma discussão em torno do conceito de sociedade da austeridade orientada pela hipótese de que à fórmula conhecida de contenção das despesas do Estado, privatização do setor público, aumento dos impostos, diminuição dos salários e liberalização do direito do trabalho corresponde uma lógica sociológica de naturalização das desigualdades. Esta lógica caracteriza-se pela cristalização das instituições e das práticas sociais em torno de uma configuração de poder resultante da combinação entre atores sociais não eleitos como a Troika e eleitos como o Governo, de uma desestabilização da estrutura normativa com recurso a um direito de exceção e de uma transformação na forma de governação orientada por um processo de legitimação tendo por base o medo.

A prioridade analítica é conferida aos temas laborais, alvo de um intenso processo reformador cujo desenvolvimento, plasmado na recente Lei n. ${ }^{\circ} 23 / 2012$, determina uma rutura com o padrão de relações laborais e de direito do trabalho vigente. $\mathrm{O}$ caso português ilustra a tentação de reduzir os padrões laborais acentuando as situações de injustiça social, exatamente o contrário daquilo que a Organização Internacional do Trabalho tem vindo a sustentar. É que embora alguns privilegiem a flexibilidade do mercado laboral como modo de contornar a gravidade e a duração do desemprego na crise atual, há evidências consideráveis, extraídas de estudos de vários países, de que não existe nenhuma relação clara entre a fraca regulação laboral e um crescimento económico e de emprego mais rápido (cf. ILO, 2009: 52).

\section{Do espírito de Filadélfia ao seu contrário}

Convido o leitor a recordar duas datas, 10 de maio de 1944 e 14 de setembro de 2008. Elas marcam simbolicamente dois processos de crise e de reforma, fixando dois padrões de transformação social opostos. A primeira corresponde ao dia da proclamação da Declaração de Filadélfia adotada pela Organização Internacional do Trabalho (OIT), na busca da reconstrução do mundo do pós-guerra, algumas semanas depois da assinatura dos acordos de Bretton Woods e 8 meses antes da conferência de Ialta (Janeiro 1945), que marcou o final da II Guerra Mundial, o mesmo ano que assiste à criação das Nações Unidas. A declaração estabelece um entendimento amplo acerca da importância da dimensão social e, muito particularmente, do 
valor do trabalho e dos seus direitos, assentes no princípio de que "o trabalho não é uma mercadoria" e na valorização deste como mecanismo de redistribuição e promoção da justiça social. Trata-se de uma circunstância relevantíssima para as décadas seguintes, em que se assiste à consolidação, nas sociedades ocidentais desenvolvidas, do designado Estado-Providência e da relação salarial fordista.

A necessidade de regular o mercado ou de preservar os mais fracos dos seus efeitos negativos está na base do consenso internacional de Filadélfia/Bretton Woods, o qual afirma a ideia de regulação internacional do económico e do social. Sem deixar de reconhecer que a história do pós-guerra é uma "era de extremos" (Hobsbawm, 1994; Judt, 2006), o "Espírito de Filadélfia" (Supiot, 2010) traduz o otimismo quanto ao "horizonte dos possíveis", às sempre limitadas oportunidades de afirmação de uma sociedade mais justa e digna onde o trabalho é indissociável dos princípios de liberdade real, de igualdade material e de produção do bem-estar. ${ }^{1}$

Quanto à segunda data, ela corresponde à falência do grupo Lehman Brothers, o quarto maior banco de negócios dos Estados Unidos, dando assim início ao colapso do sistema financeiro mundial e a uma crise que agudizou as crises económicas e sociais que se vinham manifestando desde a década de $1990 .^{2}$

As reações do G2033 (Setembro de 2008, Washington; Abril de 2009, Londres; e Setembro de 2009, São Petersburgo) pareciam atentas a este efeito multidimensional do fenómeno (financeiro, económico, de emprego, social), ao adotarem a abordagem da OIT contida no Pacto Global para o Emprego aprovado em 2009, comprometendo-se na defesa da "dimensão social da globalização”. Neste sentido, o Plano Global de Recuperação e Reforma do G20 mencionava expressamente a preocupação com a "dimensão humana da crise" e o compromisso em apoiar a construção de um mercado de trabalho justo, apoiando o emprego através do estímulo ao crescimento

\footnotetext{
${ }^{1}$ Este consenso repousa sobre uma base epistemológica que define o ator social como estando exposto a riscos de existência, o que justifica o estabelecimento de regras que visam a sua proteção, afirmando-se a responsabilidade coletiva dos sistemas de proteção social. No plano institucional, a conceção classista de sociedade vai de par com o pacto entre sindicatos e associações patronais, tornado penhor de uma sociedade de progresso. O Estado, prosseguindo o interesse geral, regulamenta e controla os mecanismos de proteção social, operando simultaneamente a mediação entre os interesses opostos do capital e do trabalho. Na esfera económica, o modelo keynesiano conduz a um entendimento do social enquanto amortecedor das crises, sendo assim redutor das mesmas e fator de crescimento (cf. Merrien, 2007: 844-854). Apesar da diversidade de modelos de Estado-Providência (Esping-Andersen, 1997), estes convergem num entendimento comum em torno das funções e papel a desempenhar pelo Estado na regulação do económico e social.

${ }^{2}$ Juan Somavia tem insistido no facto de existirem crises antes da atual crise (ILO, 2009: III).

3 http://www.ilo.org/public/libdoc/jobcrisis/download/g20_report_accelerating.pdf
} 
económico, apelando mesmo a uma intervenção ativa da OIT na realização destas medidas. Retorno ao "Espírito de Filadélfia"? A Declaração do G20 de Novembro de $2008^{4}$ esclarece a questão, ao sublinhar o dogma da economia de mercado, transformando os Estados em gigantescas companhias de seguros e aplicando medidas de cobertura dos riscos assumidos pelos bancos, evidenciando assim a crescente interdependência entre a crise financeira e as intervenções dos Estados. Dispensadas as preocupações com a questão social, o seu lugar readquire uma centralidade fulcral, mas agora enquanto sujeito de um processo de ajustamento à crise, assente na transferência contínua dos custos de recuperação para os Estados e para os cidadãos, de acordo com o paradigma da austeridade. A economia de austeridade é, como referem João Rodrigues (2011: 158) e Sandra Monteiro (2011: 195), a resposta dos Estados que materializa essa transferência para os cidadãos dos custos da recuperação do sistema financeiro, podendo ser imposta diretamente pelos poderes nacionais ou indiretamente pelos credores. Em última análise, é no esforço dos cidadãos que residem as soluções para a crise. Concomitantemente, essa transferência requer força moral e política da autoridade que fundamente o reconhecimento e a legitimação da austeridade e que constitua a razão da submissão voluntária.

Argumento que o processo de "austerização" da sociedade em geral, e da esfera laboral em particular, envolve uma dinâmica política nacional que resulta da atuação de um governo ocupado em difundir a mensagem de que "não há alternativa". Neste sentido, transmite a ideia de que a culpa pela situação em que estamos mergulhados passa por todos os indivíduos, fazendo-os "pagar" e acreditar que foram as suas ações e o seu modo de vida imprudente que contribuíram para a situação atual (cf. Bauman, 2002: 87). Com a força da nova autoridade, as reformas da austeridade levadas a cabo pelo Estado deixam perceber a dupla lógica de atuação do mesmo. Por um lado, o Estado surge como detendo o monopólio da austeridade legítima, instrumento através do qual assume as tarefas de combater a crise, impedindo a bancarrota nacional, e de proteger os indivíduos da incerteza face ao futuro. Por outro lado, aprofunda o processo de desmantelamento do Estado Social, cujo núcleo é a proteção coletiva dos danos particulares através do triplo processo de privatização dos bens públicos, de individualização dos riscos sociais e de mercadorização da vida social.

A orientação pela austeridade introduz uma nuance nas teses defendidas por Loïc Wacquant e Zygmunt Bauman, assentes na mudança paradigmática do Estado Social para o Estado Penal. Para os autores, o modelo da law and

${ }^{4}$ http://news.bbc.co.uk 
order e da justiça criminal seria induzido pela crise de legitimidade do Estado Social, que, não podendo manter os padrões de proteção e segurança social, promove uma retórica assente no abaixamento das expetativas em matéria social, propiciando em seu lugar um modelo de segurança penal através do qual adquire nova legitimidade. O Estado de Austeridade, por sua vez, não carece de trocas entre a questão social e as questões da lei e da ordem, na medida em que afirma não existirem alternativas de combate à crise, a não ser as que residem numa transferência clara dos seus custos para a sociedade. Põe, deste modo, termo à ambivalência associada à avaliação dos mecanismos de proteção social, uniformizando sob o signo da austeridade o repertório de medidas da nova ordem social: impostos, cortes salariais, cortes nas pensões e subsídios, reforma do sistema de saúde, flexibilização negativa do direito do trabalho, etc. Embora a fórmula de legitimação do Estado de Austeridade seja concordante com a do Estado Penal, isto é, coloque em estreita relação as políticas do medo, da segurança, da incerteza e da ansiedade partilhada (cf. Priban, 2007: 5), o referente muda. O "Estado de Emergência" produzido pelo medo crescente acerca da segurança pessoal face ao "desperdício humano" - imigrantes, criminosos, excluídos, etc. - dá agora lugar ao Estado de Emergência Social clamando pelo sacrifício em nome do bem comum.

\section{O sacrifício e a injustiça social}

Uma das questões frequentemente invocadas no debate político e económico a propósito da austeridade é a da equidade. Com efeito, o interesse coletivo sob a forma de esforço conjunto convoca o dilema de como combinar sacrifício e justiça social, ${ }^{5}$ conduzindo à reformulação de um problema clássico da teoria política: face à crise que a todos afeta torna-se necessário recorrer a medidas que violam os direitos fundamentais de alguns. $\mathrm{O}$ interesse e o bem comum justificam este sacrifício?

O raciocínio anterior pode ser comentado a partir de dois pontos de vista: o das perspetivas deontológicas, as quais conferem prioridade ao que é justo, ao que deve ser e à norma moral sobre o bem e as consequências das ações; e o das perspetivas consequencialistas, que fazem a escolha inversa, subordinando o justo ao bem e ao resultado das ações que maximizam o bem. ${ }^{7}$ Os primeiros não considerarão correto que, em nome do

\footnotetext{
${ }^{5}$ Na elaboração deste tópico presto especial atenção ao trabalho de Jean-Pierre Dupuy acerca do utilitarismo na obra de John Rawls (Dupuy, 1992: 107-160).

${ }^{6}$ Consultar também a este propósito René Girard (1978).

7 No sentido de aprofundar a relação entre o pensamento consequencialista e o utilitarismo, consultar Will Kymlicka (2002: 10-52), João Cardoso Rosas (2011) e Pedro Galvão (2008: 15-33). Para uma leitura sociológica do utilitarismo consultar Alain Caillé (1997: 115-146).
} 
bem coletivo, um ato injusto possa ser considerado legítimo pelo facto de as suas consequências produzirem bem-estar geral, enquanto os segundos estarão dispostos a aceitar o risco. Forçando o cânone da reflexão da teoria política, pode conceber-se a austeridade como um modelo político-liberal consequencialista e utilitarista, isto é, como um modelo em que as distribuições injustas de sacrifícios são aceitáveis, se assim se aumentar o bem- estar total ou médio. Contudo, no quadro de uma sociedade marcada por profundas desigualdades sociais, a crueza do utilitarismo que fundamenta a violação de valores e direitos e a necessidade de manutenção da "passagem dos sacrifícios" individuais para o coletivo carece de uma racionalização aceitável. Ela surge com recurso à noção de sacrifício, enquanto elemento de um contexto onde ocorreu uma "construção do consenso" que conclui pela exclusividade da resposta racional e lógica da austeridade utilitarista. É neste quadro sacrificial de partida que os seus defensores retomam o tema da equidade, invocando uma "ética social" ${ }^{8}$ com "justa repartição dos sacrifícios", 9 deixando de lado a óbvia constatação de que a distribuição desigual dos sacrifícios, numa sociedade económica e socialmente muito desigual, é vantajosa, não para o maior número de indivíduos, mas para os mais favorecidos. ${ }^{10}$

Por isso não pode causar admiração o facto de que, sendo Portugal um dos países mais assimétricos da Europa (Carmo, 2010; OCDE, 2011), os efeitos das medidas de austeridade contribuam para agudizar as desigualdades sociais. ${ }^{11}$ De acordo com um estudo realizado pela Comissão Europeia, intitulado The Distributional Effects of Austerity Measures: A Comparison of Six EU Countries (2011), a propósito da aplicação das suas recomendações, entre 2009 e julho de 2011, nos países em crise (Grécia, Portugal, Espanha, Reino Unido, Irlanda e Estónia), Portugal é o único país onde as medidas de austeridade têm exigido maior esforço financeiro aos mais pobres do que aos mais ricos. As medidas contribuíram para que os $20 \%$ mais pobres perdessem entre $4,5 \%$ e $6 \%$ dos seus rendimentos, sendo ainda mais grave

\footnotetext{
${ }^{8}$ Intervenção de Nilza Sena, deputada do PSD disponível em: http://www.dn.pt/especiais/interior.aspx? content_id=2115128\&especial=Or $\%$ E7 amento $\% 20 \mathrm{de} \% 20$ Estado $\% 20$ 2012\&seccao $=$ ECONOMIA

${ }^{9}$ Intervenção de João Almeida, deputado do CDS-PP, disponível em: http://www.dn.pt/especiais/interior.aspx? content_id=2115128\&especial=Or $\%$ E7amento $\% 20 \mathrm{de} \% 20$ Estado $\% 20$ 2012\&seccao=ECONOMIA

${ }^{10}$ Esta perspetiva político-social contraria as análises que têm insistido na importância da igualdade enquanto princípio e bem social (cf. por exemplo Pierre Rosanvalon, 2011, e Richard Wilkinson e Kate Pickett, 2010). Por seu turno, Boaventura de Sousa Santos refere a este propósito a "desmedida das medidas da austeridade" (Santos, 2011:59 ss.).

${ }^{11}$ Os PEC (2010; 2011) acabaram por ter seguimento no Orçamento de Estado e, principalmente, nos memorandos da Troika (2011).
} 
quando estes têm filhos, ascendendo as perdas até aos $9 \%$ (cf. European Commission, 2011: 21-22). Por outro lado, os $20 \%$ mais ricos perderam apenas $3 \%$ dos seus rendimentos. Os dados mostram que Portugal é o único país onde a percentagem do corte é maior nos dois escalões mais pobres da sociedade do que nos restantes, recaindo principalmente sobre os subsídios e pensões (ibidem: 16-18). Em comparação, a Grécia, que tem tido repetidos pacotes de austeridade, apresenta uma maior equidade nos sacrifícios implementados. Deste modo, os 3\% de quebra de rendimento referidos refletem sobretudo o esforço suportado por reformados e por pensionistas, seguindo-se o aumento dos impostos com encargo, principalmente, para a classe média, refletindo ainda os cortes nos salários e subsídios dos funcionários públicos (ibidem: 23-27). Em suma, trata-se da austeridade mais regressiva do conjunto dos seis países estudados, no qual o impacto na distribuição do esforço pelas classes de rendimento é mais assimétrico, penalizando os cidadãos de menores rendimentos (ibidem: 28).

\section{O poder dos eleitos, o dos não eleitos e o direito do trabalho de exceção}

"A tradição dos oprimidos ensina-nos que o 'estado de excepção' em que vivemos é a regra” (Benjamim, 1985: 157). Com estas palavras, Walter Benjamin apelava a uma interpretação do conceito de história nos termos da qual o verdadeiro estado de exceção correspondesse a uma alternativa de luta ao fascismo. É termo de referência de um debate conhecido das teorias política e do direito entre o autor e Carl Schmitt, que permanece atual e que está no cerne do conhecido livro de Giorgio Agamben, Estado de excepção (2010).

O debate releva para as discussões em torno das respostas à crise, considerando-se a constante invocação das teorias da necessidade e da exceção, em virtude das quais os princípios da austeridade constituem fontes de direito de constitucionalidade questionável.

O exercício de reflexão aqui proposto visa analisar o estado de exceção político-normativa de acordo com a hipótese de que, no atual contexto de crise, estamos a assistir a uma forma de produção do poder e do direito que tem por fonte a combinação estratégica entre atores governamentais e atores não-governamentais com o objetivo de implementar, ou mesmo institucionalizar, o modelo de austeridade utilitarista. $\mathrm{O}$ argumento geral remete para a ideia da reconfiguração do poder dos eleitos e dos não eleitos, assente na combinação entre o poder do Governo e o poder da Troika.

A problemática suscitada pelo processo de reformas associado ao pedido de financiamento externo evidencia o impacto dos memorandos da Troika na alteração de dimensões cruciais da sociedade portuguesa. Numa primeira observação do poder dos não eleitos, isto é, da Troika, este surge como fonte 
unilateral, quer na fixação dos objetivos das reformas, quer na legitimação política das mudanças. Contudo, a experiência portuguesa revela a necessidade de deslocar a análise do poder dos não eleitos para o modo como este se combina com as iniciativas do Governo, nomeadamente a interpretação extensiva que este faz do conceito de austeridade, prolongando para além do definido as medidas recessivas.

Como se sabe, as definições conhecidas da teoria da separação de poderes têm um lastro teórico e histórico, onde se devem mencionar os nomes de Locke e Montesquieu. A diversidade de soluções político-jurídicas, e a impossibilidade de explicar de uma forma sociologicamente sustentável a dinâmica dos poderes nos sistemas democráticos, conduziu a uma interpretação, não dogmática, da relação entre o princípio da separação de poderes e os contextos concretos da sua aplicação. A sociologia política e a sociologia do direito captaram esta dinâmica atendendo a diferentes formas de combinação entre poderes políticos e poderes sociais que envolvem partidos políticos, manifestações de pluralismo político (através de grupos de pressão ou de interesses), manifestações de neocorporativismo, governação neoliberal, autorregulação, ${ }^{12}$ a que acrescem, ainda, os fenómenos da judicialização da política, da politização da justiça, do uso alternativo do direito, do ativismo judicial e do direito dos juízes.

A perspetiva de análise do poder dos não eleitos constitui um desenvolvimento recente desta problemática. Nas democracias modernas, os organismos não eleitos tomam muitas das decisões que afetam a vida das pessoas, solucionando conflitos de interesses fraturantes da sociedade, resolvendo disputas sobre a alocação de recursos, efetuando julgamentos éticos relativos a áreas política e culturalmente sensíveis da sociedade. O exemplo da Grécia e da Itália, onde os governos foram forçados a demitir-se para dar lugar a novos governos de caráter tecnocrático à margem de qualquer processo eleitoral, é muito demonstrativo da força dos não eleitos: um mundo constituído por variadas expressões que incluem mercados, organizações financeiras internacionais, bancos centrais, agências de regulação, agências de rating, etc. ${ }^{13}$ (Vibert, 2007: 1).

Entre nós, a nebulosa constituída pelo FMI, BCE e CE remete para funções e competências que nem todos os cidadãos saberiam definir com

\footnotetext{
${ }^{12}$ Outros conceitos a ter em conta são os de lobby, influência, corrupção, poder da comunicação social ou quarto poder, teorias da conspiração e os cripto-poderes de que fala Norberto Bobbio (1988: 109-140).

${ }^{13}$ O fenómeno das agências de rating enquanto expressão do poder dos não eleitos é muito significativo. Como se sabe, contrariam o poder de Estados centrais como os Estados Unidos ou blocos como a União Europeia. Têm desempenhado um papel determinante no contexto da atual crise, que não será alvo de análise neste estudo.
} 
rigor, tendo, no entanto, a exata perceção da sua importância sob a fórmula Troika, quando esta é invocada por políticos eleitos para lidar com a complexidade da crise e das políticas públicas. A influência de organizações não eleitas sobre os Estados nacionais não é um fenómeno novo, dado que, desde a década de 1980, as reformas neoliberais têm sido orientadas na arena internacional por organizações não estatais. Essa influência ganha, contudo, contornos radicais no atual contexto de crise.

\subsection{Interpelações ao Estado de Direito}

Identifico de seguida três questões que se colocam à teoria democrática e à teoria do direito pelo poder dos não eleitos, tendo presente as medidas constantes dos memorandos da Troika e as iniciativas legislativas do Governo em matéria laboral.

Em primeiro lugar, a interpelação ao Estado de Direito. No momento em que somos confrontados com os efeitos da austeridade, provocados pelas reformas postas em ação pela constelação de poderes dos eleitos e dos não eleitos, torna-se inevitável questionar a atividade do Estado na sua função de controlo da legitimidade e da legalidade. É esse o sentido do conceito de Estado de Direito: "um Estado ou uma forma de organização político-estadual cuja atividade é determinada e limitada pelo direito" (Canotilho, 1999: 4), baseando-se as medidas tomadas na lei, isto é, em diploma aprovado pela própria nação através dos seus representantes (cf. Guibentif, 2008: 83). A raiz nacional do Estado de Direito é elemento integrante da modernidade constitucional, na medida em que "o Estado atua sobre os cidadãos segundo as regras definidas pelos mesmos cidadãos; ou seja, através do estado de direito, a cidadania age sobre si própria" (Guibentif, 2008: 84). ${ }^{14}$

É certo que as evoluções recentes do Estado de Direito caminham há muito no sentido de alterar a sua posição na geografia dos poderes, pondo em causa o modo de regulação político tradicional (Arnaud, 2003; Santos, 2006; 2009), por via da crescente influência das entidades supranacionais e do paradigma da governação neoliberal. Por essa razão, importa identificar o que se pode designar por duplo "paradoxo da soberania", provocado pela nova configuração de poderes: (1) o facto de a soberania se encontrar ao mesmo tempo dentro e fora da ordem política nacional; (2) o facto de a soberania se encontrar ao mesmo tempo dentro e fora da ordem jurídica (cf. Agamben, 1998: 15).

${ }_{14}$ Pierre Guibentif ilustrou este argumento recorrendo à Declaração dos Direitos do Homem e do Cidadão de 26 de agosto 1789 , invocando respetivamente, os artigos $5 .^{\circ}$ e $6 .^{\circ}$. 
Especulando a este respeito e aplicando o raciocínio à nova configuração de poderes, pode afirmar-se que o questionamento do Estado de Direito é o que resulta de uma autossuspensão da soberania pela soberania, ${ }^{15}$ e de um direito que se coloca fora da lei através dele próprio. ${ }^{16}$ É com base nestas duas premissas político-jurídicas que se constitui o mecanismo que permite a articulação entre o poder dos eleitos e o poder dos não eleitos. As lógicas combinatórias entre ambos resultam em reformas orientadas pelo princípio da incerteza e pela indeterminação. Estando próximos das origens da incerteza e sendo a sua própria conduta fonte de incerteza para a situação de outros, o exercício do poder governativo encontra-se, deste modo, livre para fixar o regime de exceção da soberania e do direito. ${ }^{17}$ Por outro lado, a indeterminação quanto à verdadeira fonte das reformas, os memorandos da Troika ou a agenda política nacional do Governo português, gera uma unidade de medida na intervenção governamental dificilmente sujeita ao contraditório. Onde começam os requisitos da Troika e acaba o programa neoliberal do Governo? Esta ambiguidade permite levar a cabo um processo de reformas radicais do Estado e da sociedade portuguesa sob o signo da austeridade sem que se enunciem os seus limites, se é que eles existem.

\subsection{A separação de poderes e a jurisprudência da austeridade}

Em segundo lugar, com a nova separação de poderes estamos perante uma "classe executiva" organizacional, de base internacional, que intervém na criação de direito, apresentando-se como uma "meta-fonte" de legitimidade em conflito com as regras da democracia representativa, e que tende a ofuscar, ou mesmo afastar, o procedimento de controlo recíproco entre os poderes legislativo, executivo e judicial. Como demonstra a experiência portuguesa, sob estas condições, a relação entre o poder executivo e legislativo, ao ocorrer no âmbito de governos maioritários, tende a limitar a capacidade de interferência das oposições. A eficácia das suas atuações não impede a promulgação de legislação de exceção. Menos previsível, e a deixar antever uma centralidade renovada, é a situação do poder judicial.

\footnotetext{
${ }_{15}$ No sentido de que é o Estado Soberano que troca a sua soberania pelo apoio da Troika.

${ }^{16}$ Cf. Giorgio Agamben (1998; 2010).

${ }_{17}$ A observação de Michel Crozier acerca da dominação é pertinente e continua atual: "as pessoas que conseguem manter as suas ações sem vínculos, sem normas e imprevisíveis, enquanto regulam normativamente (rotinizando, e assim tornando monótonas, repetitivas e previsíveis) as ações dos seus protagonistas, governam. As pessoas cujas mãos não estão atadas governam sobre as pessoas cujas mãos estão atadas; a liberdade dos primeiros é a principal razão da falta de liberdade dos segundos - enquanto que a falta de liberdade dos segundos é a causa da liberdade dos primeiros" (Crozier apud Bauman, 2000: 119).
} 
No quadro das suas funções (Santos et al., 1996: 51-56), a atividade dos tribunais, no contexto de crise, revela a existência de uma jurisprudência da "austeridade" que tem por objeto o direito de exceção. É sabido que os tribunais desempenham um forte papel de racionalização da legislação, tanto maior quanto ela assuma um caráter politicamente controvertido. Do ponto de vista político, a sua capacidade de ponderação sobre a atividade dos poderes executivo e legislativo torna-os sujeitos ativos na atual fase de transformação da sociedade portuguesa.

A atuação da justiça constitucional na fiscalização da atividade política ganha realce com o pedido de apreciação da constitucionalidade, relativo à Lei do Orçamento de Estado de 2011. Neste caso, o Acórdão n..$^{\circ}$ 396/2011 ${ }^{18}$ considera que "intentando-se até por força de compromisso com instâncias europeias e internacionais, conseguir resultados a curto-prazo, foi entendido que, pelo lado da despesa, só a diminuição de vencimentos garantia eficácia certa e imediata, sendo, nessa medida, indispensável”. Acrescenta ainda que "não havendo razões de evidência em sentido contrário e dentro de 'limites do sacrifício', que a transitoriedade e os montantes das reduções ainda salvaguardam, é de aceitar que essa seja uma forma legítima e necessária, dentro do contexto vigente, de reduzir o peso da despesa do estado, com a finalidade de reequilíbrio orçamental". No caso concreto, a justiça constitucional não funcionou como uma instituição "contra as maiorias" (Araújo e Magalhães, 2000), apesar das declarações de voto vencido de alguns conselheiros, que consideraram a inconstitucionalidade do diploma em apreço por violação do princípio do Estado de direito democrático em conjugação com os princípios da igualdade e da confiança. ${ }^{19}$

Também os tribunais de 1 . $^{a}$ Instância têm sido chamados a apreciar as medidas de exceção, pronunciando-se, no entanto, em sentido contrário ao do Tribunal Constitucional. Assim, o Tribunal de Trabalho de Lisboa indeferiu o pedido de redução de retribuições e congelamento na progressão da carreira dos trabalhadores dos CTT, tendo concluído a sentença pela inconstitucionalidade material das normas do Orçamento de Estado para 2011 e pela violação do princípio da igualdade dos cidadãos perante a lei (Processo n. ${ }^{\circ} 144 / 11.8 \mathrm{ttl}$ sb).

${ }^{18}$ Conferir Diário da República n. ${ }^{\circ} 199$ - 2. ${ }^{a}$ série (17 de outubro de 2011).

19 Conferir artigo 2. ${ }^{\circ}$ da Constituição, em conjugação com o disposto no artigo $13 .^{\circ}, \mathrm{n} .{ }^{\circ} 1 \mathrm{e} 2$, e no artigo $59 .^{\circ}, \mathrm{n} .^{\circ} 1$, alínea a). Aguarda-se a posição do Tribunal Constitucional a novo pedido de fiscalização sucessiva da constitucionalidade do Orçamento de Estado de 2012. 


\subsection{O direito do trabalho de exceção}

Em terceiro lugar, com a ação conjugada das interpelações ao Estado de Direito e ao mecanismo de separação de poderes, ameaça-se o princípio do direito democrático, ao substitú-lo por um outro baseado em normas pretensamente naturais e técnicas (cf. Hespanha, 2007: 83). O direito daqui emergente segue os padrões do atual capitalismo financeiro como um modelo forçoso de organização das relações, não apenas económicas, mas humanas em geral. O direito de exceção surge agora como incontornável, não podendo contra ele valer a soberania popular ou o princípio da produção democrática do direito (ibidem: 84-86). Projetando-se como direito líquido, no sentido de Bauman, prescinde dos predicados da previsibilidade, da segurança e da confiança, transmutando-se em instrumento de dominação da nova configuração de poderes.

A excecionalidade deste direito faz parte do processo de "austerização" suportado por uma racionalidade instrumental e de cálculo custo-benefício, a qual liquidifica e fragiliza os obstáculos colocados pelo direito até então vigente (cf. Priban, 2007: 1). Este fenómeno é particularmente evidente na esfera laboral, onde o direito de exceção se apresenta em rutura paradigmática com os pressupostos do direito do trabalho, eliminando o conflito enquanto elemento dinâmico das relações laborais e a proteção do trabalhador enquanto condição de liberdade. As funções protetoras do direito do trabalho são questionadas, nomeadamente, quando se altera de uma forma radical as questões relacionadas com o tempo de trabalho e descanso, se facilita o processo de despedimento e se minimiza o papel da negociação coletiva.

No quadro deste argumento, sustento que a função económico-instrumental do direito do trabalho é marcada desde meados dos anos 1940 por três fases. A primeira, a do fordismo, a qual terá correspondido ao momento de maior afirmação do status sobre o contrato, é ultrapassada com a sua crise pela fase de flexibilização e de neoliberalização do direito do trabalho, que conduziu a uma solução de sentido inverso. Nesta fase, a tensão entre o fordismo e o neoliberalismo laboral ficou ainda marcada por uma simbiose entre a flexibilização legal e o recurso a práticas sociais à margem da lei por parte dos empregadores. É com este fenómeno, que designo noutro lugar por direito do trabalho subversivo (Ferreira, 2012a; 2012b), que chegamos à crise de 2008 e ao surgimento do direito do trabalho de exceção. $\mathrm{Na}$ atualidade, o tempo de austeridade e a afirmação do direito do trabalho de exceção marcam o surgimento de uma nova tendência pautada pela redução, ou mesmo resolução, das descoincidências entre law in books e law in action, ao fundirem no direito do trabalho 
de exceção o aprofundamento da flexibilidade legal e a legalização das práticas sociais ilegítimas.

Legalizar o contrato leonino, na medida em que o poder fáctico e as práticas ilegais extracontratuais passam a ser direito, constitui um objetivo a atingir mesmo que para isso tenha de se negar as funções antropológicas e sociológicas do direito do trabalho (Supiot, 2006: 9-10). Em nome do realismo da austeridade não se hesita em "matar no homem a pessoa jurídica" (Arendt, 1978: 381-383), expulsando do direito as considerações de justiça. A ressonância schmittiana ${ }^{20}$ do argumento não é despropositada na esfera laboral face à implementação em curso das medidas elaboradas pela Troika ${ }^{21}$ e aceites pelo Governo português. Considere-se que no atual momento as reformas da legislação inscreveram no direito do trabalho algo de essencialmente exterior a ele, ou seja, nada menos do que a eliminação da sua identidade político-jurídica em troca de um financiamento externo. O direito do trabalho torna-se, assim, num produto de mercado utilizado como caução do apoio externo. Mas simultaneamente, ao serem-lhe retiradas as notas da conflitualidade e da correlação de forças entre os parceiros sociais como fatores constitutivos de uma busca de equilíbrios sui generis, impondo em seu lugar um reordenamento do sistema de deveres e obrigações, franqueia-se o caminho a estruturas hierárquicas capazes de proceder ao último ajuste político-ideológico do direito do trabalho gerado depois de 1974.

\section{As narrativas de conversão e medo social}

A revista Times ${ }^{22}$ ao atribuir o prémio de pessoa do ano à figura do "protestante”, reconheceu a importância dos movimentos de contestação surgidos como reação às atribulações geradas pela crise. Na memória estão igualmente as imagens das manifestações (violentas) na Grécia ou em Portugal, que têm expressado o descontentamento face às medidas tomadas em nome da austeridade. As expressões do conflito não precludem, todavia, uma leitura do social orientada pela abordagem das sociologias do controlo social, as quais identificam os processos de legitimação e as formas de consentimento ativo ou passivo, intencional ou não intencional, assentes na gestão das motivações e expectativas dos indivíduos (Sciulli, 1992). Questão relevante considerando-se que só na esfera laboral as reformas orientadas pela austeridade recuperam numa versão musculada e aumentada a agenda

${ }^{20}$ A este propósito conferir Giorgio Agamben, Estado de excepção (2010).

${ }^{21}$ Disponível em: http://www.imf.org/external/np/loi/2011/prt/por/051711p.pdf

${ }^{22}$ http://www.time.com/time/person-of-the-year/2011/ 
neoliberal dos anos 1980 do eixo Reagan-Thatcher, com a penhora do direito do trabalho, implementação de medidas de flexibilidade negativa ${ }^{23}$ e desqualificação dos sindicatos. Mesmo a linha ténue estabelecida entre a função protetora do direito do trabalho e a sua reestruturação neoliberal dos anos 1990, matizada pelos "trade-offs equilibrados" da flexigurança e dos mercados transicionais em definitivo, é ultrapassada.

Face a este contexto, a legitimação pelo medo, induzido através de previsões de cenários catastróficos, afirma-se como mecanismo de conversão da narrativa da austeridade em modelo político-social dominante, assegurando a prioridade absoluta dos valores morais do neoliberalismo económico e laboral (Somers, 2008: 3). Esta forma particular de organizar a vida social confere centralidade ao medo como valor cultural orientador das expectativas e práticas sociais ${ }^{24}$ dos indivíduos, enformadas, no dizer poético de Mia Couto, pela ideia de que "há mais medo de coisas más do que coisas más propriamente ditas", acompanhada pela ideia de que "há quem tenha medo que o medo acabe". ${ }^{25} \mathrm{O}$ medo e o distopismo são, assim, constitutivos das narrativas de conversão, operando a fusão entre os níveis coletivo e individual, transformando o modo como se vive na solução biográfica para as contradições sistémicas (cf. Bauman, 2002: 88). ${ }^{26}$ Os sinais de inquietação que encerram os indivíduos nas narrativas de conversão da austeridade estão à vista: falta de confiança nos governos nacionais; consciência da degradação das condições de vida; insatisfação com o Estado livre e democrático; perceção de que a economia nacional não vai melhorar; falta de acesso aos canais de comunicação e participação (cf. ILO, 2011: 25). No mesmo sentido, um estudo da Gallup (2011) regista um aumento significativo de 2009 para 2010, por parte dos trabalhadores norte-americanos, no que toca ao receio de perder o emprego, indicando que 3 em cada 10 trabalhadores têm

\footnotetext{
${ }^{23}$ Numa interpretação crítica do conceito, Hermes Costa chama a atenção para a ambiguidade semântica (2008:34) que se lhe encontra associada, sendo nesse registo que utilizo a noção de flexibilidade negativa, entendida como minimização da função tuitiva do Estado e de proteção do direito do trabalho com afastamento dos procedimentos associados à democracia laboral - diálogo social, negociação coletiva, participação dos trabalhadores - visando o objetivo do bom funcionamento do mercado.

${ }^{24}$ A este propósito, o conceito de medo é analisado por autores como Zygmunt Bauman (2006) e Robert Castel (2003), refletindo o enfraquecimento dos vínculos sociais resultantes de uma insegurança ontológica e social crescentes.

${ }_{25}$ A este propósito conferir: http://www.conferenciasdoestoril.com/artigo.aspx?lang=pt\&id_ object=525\&name=Mia-Couto. $\mathrm{O}$ autor inspirou-se em Eduardo Galeano (cf.: http://www.lainsignia.org/2001/abril/cul_022.htm).

${ }^{26}$ A este propósito confira-se: "Somos todos responsáveis. Esta é a hora em que todos os portugueses são chamados a dar o seu melhor para ajudar Portugal a vencer as dificuldades." (Mensagem de Ano Novo do Presidente da República, 1 de janeiro de 2012. Disponível em http://www. presidencia.pt/?idc=22\&idi $=60565$ ).
} 
medo de ser dispensados da sua empresa. $\mathrm{O}$ argumento conclusivo do estudo recai sobre o impacto psicológico dos problemas económicos do país sobre os trabalhadores, revelando que a resignação é o sentimento dominante e que a esperança na recuperação económica é pouca ou quase nenhuma. ${ }^{27}$

As narrativas de conversão exercem ainda um enorme poder na fixação das agendas de discussão e tomadas de posição dos atores sociais coletivos, já que as assunções públicas de que são portadoras estão incorporadas e naturalizadas na cultura política dominante, estabelecendo os parâmetros legítimos para o que realmente interessa nos debates políticos e sociais (cf. Somers, 2008: 2). A narrativa da austeridade caracterizada pelo fundamentalismo de mercado faz com que entendimentos alternativos da realidade sejam deslegitimados, questionando-se quaisquer agendas legislativas que contenham a aceitação de um ethos social como destino partilhado, risco igualitário e justiça social (ibidem: 3). Deste modo, as instituições e organizações da cidadania social podem ser conquistadas e convertidas. O recente acordo de concertação social é ilustrativo deste processo, quer pela permanente ameaça exercida sobre os sindicatos, quer pela interiorização por parte dos sindicatos signatários do acordo de que não existiam alternativas. A concertação social foi, assim, capturada pela narrativa da austeridade, colocando-se em linha com o amplo processo de recontratualização do mundo do trabalho em curso.

\section{Conclusão}

O objetivo deste artigo foi o de contribuir para uma discussão em torno do conceito de sociedade da austeridade. Valorizei as dimensões relacionadas com a lógica social de articulação dos indivíduos com os factos sociais que se lhes apresentam como externos e com uma força constrangedora inusitada. Realcei, igualmente, o contexto de excecionalidade na ótica da sua combinação com os fundamentos da legitimidade das decisões políticas, formas de exercício do poder e de produção do direito do trabalho de exceção.

A crítica do direito do trabalho de exceção tem de contrariar a tendência para conceber o direito de uma forma não problemática e consensual, na qual assenta o entendimento de que, se um direito é protegido pela lei, a interferência de outro ator no exercício desse direito será constrangida pelas autoridades.

Mas o direito do trabalho de exceção é "sociologicamente problemático", por pretender naturalizar a ideia de a disputa entre direitos ocorrer

${ }_{27}$ Disponível em: http://www.gallup.com/poll/149261/Worries-Job-Cutbacks-Return-Record-Highs.aspx 
entre iguais ou entre pessoas que tenham um mesmo acesso aos meios de os assegurarem, no quadro de uma dinâmica identificada como "consenso de ponderação de poder" (Coleman apud Barbalet, 1998: 187). O efeito do falso reconhecimento, ou não-direito, é o de que grupos com objetivos e interesses manifestamente conflituais são integrados num sistema jurídico consensual, onde ao reconhecimento não corresponde a reciprocidade dos interesses conflituais dos grupos e indivíduos. A falácia reside na anulação do caráter conflitual das relações laborais e do direito do trabalho, bem como das funções de proteção da parte mais vulnerável.

\section{Referências bibliográficas}

Agamben, Giorgio (1998), Homo Sacer: Sovereign Power and Bare Life. Standford: Stanford University Press.

Agamben, Giorgio (2010), Estado de excepção. Lisboa: Edições 70.

Araújo, António de; Magalhães, Pedro Coutinho (2000), "A justiça constitucional: uma instituição contra as maiorias?”, Análise Social, 154-155, 207-246.

Arendt, Hannah (1978), O sistema totalitário. Lisboa: Publicações Dom Quixote.

Arnaud, André-Jean (2003), Critique de la raison juridique. Paris: LGDJ.

Barbalet, J. M. (1998), Emoção, teoria social e estrutura social - Uma abordagem macrossocial. Lisboa, Instituto Piaget.

Bateson, Gregory (1987), Natureza e espírito: uma unidade necessária. Lisboa: Publicações D. Quixote.

Bauman, Zygmunt (2000), Liquid Modernity. Cambridge: Polity Press.

Bauman, Zygmunt (2002), A sociedade sitiada. Lisboa: Instituto Piaget.

Bauman, Zygmunt (2006), Confiança e medo na cidade. Lisboa: Relógio D’Água Editores.

Benjamin, Walter (1985), "Teses sobre filosofia da história”, in Flávio Kothe (org.), Walter Benjamin Sociologia, 153-164.

Bobbio, Norberto (1988), O futuro da democracia. Lisboa: Publicações Dom Quixote. Caillé, Alain (1997), A demissão dos intelectuais. Lisboa: Edições Piaget.

Canotilho, José Joaquim Gomes (1999), Estado de direito. Lisboa: Gradiva Publicações.

Carmo, Renato Miguel do (org.) (2010), Desigualdades sociais 2010, estudos e indicadores. Lisboa: Editores Mundos Sociais.

Castel, Robert (2003), L'insécurité sociale: qu'est-ce qu'être protégé ? Paris: Seuil et La République des Idées.

Costa, Hermes (2008), Sindicalismo global ou metáfora adiada. Coimbra: Edições Afrontamento.

Dahrendorf, Ralf (1995), A quadratura do círculo. Lisboa: Edições 70.

Dornelas, António (coord.) (2006), Livro verde sobre as relações laborais. Lisboa: Ministério do Trabalho e da Solidariedade Social. 
Dupuy, Jean-Pierre (1992), Le sacrifice et l'envie. Le libéralisme aux prises avec la justice sociale. Paris: Calmann-Lévy.

Esping-Andersen, Gosta (1997), Les trois mondes de L'état providence. Paris: Puf.

Estanque, Elísio (2009), "Diferenças sociais de classe e conflitualidade social”, in Mário Lages e Artur Teodoro Matos (orgs.), Portugal intercultural: razão e projecto. Lisboa: CEPCEP-Universidade Católica Portuguesa/ACIDI - Alto Comissariado para a Integração e Desenvolvimento Intercultural, 2009, 123-176.

European Commission (2011), The Distributional Effects of Austerity Measures: A Comparision of Six EU Countries. Social Situation Observatory - Income Distribution and Living Conditions.

Ferreira, António Casimiro (2012a), Sociedade da austeridade e o direito do trabalho de exceção. Porto: Vida Económica.

Ferreira, António Casimiro (2012b), O trabalbo e os seus direitos: perspectivas da sociologia do direito do trabalho (no prelo). Coimbra: Almedina.

Galvão, Pedro (2008), "Utilitarismo”, in João Cardoso Rosas (org.), Manual de filosofia política. Coimbra: Almedina, 15-33.

Girard, René (1978), Des choses cachées depuis la fondation du monde. Paris: Éditions Grasset \& Fasquelle.

Guibentif, Pierre (2008), "Estado de direito e Estado penal - Vicissitudes de um relacionamento", in José Madureira Pinto e Virgílio Borges (orgs.), Desigualdades, desregulação e riscos nas sociedades contemporâneas. Porto: Edições Afrontamento, 81-102.

Hespanha, António (2007), O caleidoscópio do direito. O direito e a justiça nos dias e no mundo de hoje. Coimbra: Almedina.

Hobsbawm, Eric (1994), A era das revoluções. Lisboa: Editorial Presença.

ILO (2009), The Financial and Economic Crisis: A Decent Work Response. Genebra: International Institute for Labour Studies.

ILO (2011), World of Work Report 2011: Making Work for Jobs. Genebra: International Institute for Labour Studies.

Judt, Tony (2006), O mundo pós-guerra. Lisboa: Edições 70.

Kymlicka, Will (2002), Contemporary Political Philosopby: An Introduction. Oxford: Oxford University Press.

Merrien, François-Xavier (2007), "Les devenirs de la solidarité sociale”, in Serge Paugam (org.), Repenser la solidarité. L'apport des sciences sociales. Paris: Puf, 839-886.

Monteiro, Sandra (2011), “O austeritarismo, mutação do pensamento único”, in José Reis e João Rodrigues (orgs.), Portugal e a Europa em crise. Para acabar com a economia de austeridade. Lisboa: Actual Editora, 195-199.

OCDE (2011), Divided We Stand: Why Inequality Keeps Rising. Disponível em: http:// www.oecd.org/document/51/0,3746,en_2649_33933_49147827_1_1_1_1,00.html Přibáň, Jiří (org.) (2007), Liquid Society and Its Law. Aldershot, Hampshire/Burlington, VT: Ashgate. 
Rebelo, Glória (2004), Flexibilidade e precariedade no trabalho. Análise e diagnóstico. Lisboa: Fundação para a Ciência e Tecnologia/Ministério da Ciência e do Ensino Superior.

Rodrigues, João (2011), "A economia política da austeridade orçamental”, in José Reis e João Rodrigues (orgs.), Portugal e a Europa em crise. Para acabar com a economia de austeridade. Lisboa: Actual Editora, 157-164.

Rosanvallon, Pierre (2011), La société des égaux. Paris: Seuil.

Rosas, João Cardoso (2011), Concepções de justiç̧a. Lisboa: Edições 70.

Santos, Boaventura de Sousa; Marques, Maria Manuel Leitão; Pedroso, João; Ferreira, Pedro Lopes (1996), Os tribunais nas sociedades contemporâneas: o caso português. Porto: Edições Afrontamento.

Santos, Boaventura de Sousa (2006), A gramática do tempo. Para uma nova cultura politica. Porto: Afrontamento.

Santos, Boaventura de Sousa (2009), Sociología Jurídica Crítica. Para un nuevo sentido comin en el derecho. Madrid: Editorial Trotta.

Santos, Boaventura de Sousa (2011), Portugal. Ensaio contra a autoflagelação. Coimbra: Almedina.

Sciulli, David (1992), Theory of Societal Constitutionalism: Foundations of a Non-marxist Critical Theory. Cambridge: University Press.

Somers, Margaret (2008), Genealogies of Citizenship: Markets, Statelessness, and the Right to Have Rights. Cambridge: Cambridge University Press.

Supiot, Alain (2010), L'esprit de Philadelphie: la justice sociale face au marché total. Paris: Éditions Seuil.

Supiot, Alain (2006), Homo Juridicus: ensaio sobre a função antropológica do direito. Lisboa: Instituto Piaget.

Vibert, Frank (2007), The Rise of the Unelected: Democracy and the New Separation of Powers. Cambridge: Cambridge University Press.

Wilkinson, Richard; Pickett, Kate (2010), O espirito da igualdade: por que razão sociedades mais igualitárias funcionam quase sempre melhor. Lisboa: Editorial Presença. 